\title{
EFFECTS OF GLUTAMATE AND ASPARTATE ON MYOCARDIAL SUBSTRATE OXIDATION DURING POTASSIUM ARREST
}

Mark K. Reed, MD

Chen Barak, $\mathrm{PhD}$

Craig R. Malloy, MD

Stephen P. Maniscalco, MD

Michael E. Jessen, MD
Objectives: A recent report (J Clin Invest 1993;92:831-9) found no effect of glutamate plus aspartate on metabolic pathways in the heart, but the experimental conditions did not model clinical cardioplegia. The purpose of this study was to determine the effects of glutamate and aspartate on metabolic pathways feeding the citric acid cycle during cardioplegic arrest in the presence of physiologic substrates. Methods: Isolated rat hearts were supplied with fatty acids, lactate, pyruvate, glucose, and acetoacetate in physiologic concentrations. These substrates were enriched with ${ }^{13} \mathrm{C}$, which allowed a complete analysis of substrate oxidation by ${ }^{13} \mathrm{C}$-nuclear magnetic resonance spectroscopy in one experiment. Three groups of hearts were studied: arrest with potassium cardioplegic solution, arrest with cardioplegic solution supplemented with glutamate and aspartate (both in concentrations of $13 \mathrm{mmol} / \mathrm{L}$ ), and a control group without cardioplegic arrest. Results: In potassium-arrested hearts, the contributions of fatty acids and lactate to acetyl coenzyme $A$ were reduced, and acetoacetate was the preferred substrate for oxidation in the citric acid cycle. The addition of aspartate and glutamate in the presence of cardioplegic arrest did not further alter patterns of substrate utilization substantially, although acetoacetate use was somewhat lower than with simple cardioplegic arrest. When $\left[\mathrm{U}-{ }^{13} \mathrm{C}\right] \mathrm{glu}-$ tamate $(13 \mathrm{mmol} / \mathrm{L})$ and $\left[\mathrm{U}^{-13} \mathrm{C}\right]$ aspartate $(13 \mathrm{mmol} / \mathrm{L})$ were supplied as the only compounds labeled with ${ }^{13} \mathrm{C}$, little enrichment in citric acid cycle intermediates could be detected. Conclusions: Glutamate and aspartate when added to potassium cardioplegic solutions have relatively minor effects on citric acid cycle metabolism. (J Thorac Cardiovasc Surg 1996;112:1651-60)
A popular modification of potassium cardioplegic solutions has been the addition of glutamate and aspartate. Although improved myocardial perfor-

From the Departments of Surgery (Division of Thoracic and Cardiovascular Surgery), Internal Medicine (Division of Cardiology), and Radiology, the University of Texas Southwestern Medical Center at Dallas, the Dallas Veterans Affairs Medical Center, Dallas, Tex., and the Joint Program in Biomedical Engineering, University of Texas at Arlington, Arlington, Tex.

Received for publication April 22, 1996; revisions requested June 7, 1996; revisions received June 24, 1996; accepted for publication June 24, 1996.

Supported by Grant-in-Aid 94013300 from the American Heart Association, the Southwestern Biomedical Magnetic Resonance Facility Grant (NIH P41 RR-02584), and the Department of Veterans Affairs Clinical Investigator Program.

Presented in part at the Eightieth Clinical Congress of the American College of Surgeons, October 1994.

Address for reprints: Michael E. Jessen, MD, Division of Thoracic and Cardiovascular Surgery, University of Texas Southwestern Medical Center, 5323 Harry Hines Blvd., Dallas, TX 75235-8879.

$12 / 1 / 76045$ mance after ischemia was found in rats, ${ }^{1-3}$ rabbits, ${ }^{4,5}$ dogs, ${ }^{6,7}$ cats, $^{8}$ pigs, ${ }^{9}$ and human beings, ${ }^{10,11}$ the mechanism remains uncertain. Because these compounds are transaminated to oxaloacetate and $\alpha$-ketoglutarate, both citric acid cycle intermediates, maintenance of high-energy phosphates has been postulated owing to metabolism of these amino acids. ${ }^{12}$ For example, high concentrations of $\alpha$-ketoglutarate may drive production of high-energy phosphates by substrate level phosphorylation in the succinate thiokinase reaction. ${ }^{13}$ Sanborn and associates $^{12}$ emphasized that the overall stoichiometry of metabolism of both glutamate and aspartate to succinate would allow the redox state to remain constant if anaerobic glycolysis continued. Other investigators have suggested that the effects of glutamate may be indirect and mediated by a shift in substrate utilization away from free fatty acids. ${ }^{14}$

These hypotheses require that carbon skeletons from aspartate or glutamate enter the citric acid cycle or that the sources of acetyl coenzyme $A$ 
Table I. Composition of mixed fatty acids used in perfusates compared with those found in rat triglyceride stores

\begin{tabular}{lccc}
\hline \multicolumn{1}{c}{ Fatty acid } & Structure & $\begin{array}{c}\text { Perfusate } \\
(\%)\end{array}$ & $\begin{array}{c}\text { Triglycerides }^{30} \\
(\%)\end{array}$ \\
\hline Pentadecanoic & $15: 0$ & 2.9 & $<2$ \\
Palmitic & $16: 0$ & 20.2 & 23 \\
Palmitoleic & $16: 1$ & 6.1 & 4.7 \\
Hexadecadienoic & $16: 2$ & 8.8 & $<2$ \\
Hexadecatrienoic & $16: 3$ & 7.1 & $<2$ \\
Stearic & $18: 0$ & 1.8 & 5.7 \\
Oleic & $18: 1$ & 12.1 & 35.0 \\
Linoleic & $18: 2$ & 27.6 & 24.7 \\
Linolenic & $18: 3$ & 13.4 & $<2$ \\
Total & & 100.0 & 93.1 \\
\hline
\end{tabular}

The relative concentrations of fatty acids supplied by the manufacturer (perfusate) is compared with literature values for fatty acids in rat triglycerides.

(acetyl $\mathrm{CoA}$ ) be altered. However, these pathways supplying the citric acid cycle are seldom quantified. An important exception was the observation that ${ }^{14} \mathrm{C}$-labeled succinate was generated from both $\left[\mathrm{U}_{-}{ }^{14} \mathrm{C}\right]$ glutamate* and $\left[\mathrm{U}_{-}{ }^{14} \mathrm{C}\right]$ aspartate. ${ }^{12}$ In contrast, a recent report ${ }^{15}$ found little metabolic effect of glutamate plus aspartate. The relevance of either study to cardiac surgical conditions is uncertain, because neither potassium cardioplegia nor physiologic substrates were used.

The current study examined the effects of potassium arrest on selection of substrates for oxidation and the effect of aspartate plus glutamate on the profile of substrate oxidation in the presence of potassium cardioplegia. Somewhat unexpectedly, potassium cardioplegia shifted the sources of acetyl $\mathrm{CoA}$, but supplementation with glutamate and aspartate had little further effect.

\section{Methods}

Materials. Sodium $\left[3-{ }^{13} \mathrm{C}\right] \mathrm{L}-$-lactate, sodium $\left[3-{ }^{13} \mathrm{C}\right] \mathrm{py}-$ ruvate, and $\left[\mathrm{U}^{13} \mathrm{C}\right] \mathrm{L}-$ glutamic acid were purchased from Cambridge Isotopes Inc., Woburn, Massachusetts. [1,3${ }^{13}$ C]Acetoacetate (prepared by alkaline hydrolysis from the ethyl ester) and $\left[\mathrm{U}^{-13} \mathrm{C}\right] \mathrm{L}$-aspartate were obtained from Isotec Inc., Miamisburg, Ohio. All of these compounds were enriched to $99 \%$. Unenriched and $\left[\mathrm{U}-{ }^{13} \mathrm{C}\right]$ (99\%) mixed free fatty acids were purchased from Martek Inc., Columbia, Maryland. The composition of the labeled mixed fatty acids used was similar to that of the fatty acids found in rat lipid stores (Table I).

\footnotetext{
${ }^{*}$ The expression [U- ${ }^{14} \mathrm{C}$ ]glutamate refers to a glutamate molecule with all carbon atoms uniformly labeled with the isotope, in this case ${ }^{14} \mathrm{C}$.
}

Experimental animals. Male Sprague-Dawley rats (three groups of eight each) weighing 250 to $350 \mathrm{gm}$ were given food and water ad libitum. All animals were cared for in compliance with the "Guide for the Care and Use of Laboratory Animals" prepared by the Institute of Laboratory Animal Resources (National Academy of Sciences) and published by the National Institutes of Health (NIH Publication No. 86-23, revised 1985).

Heart perfusions. Rats were anesthetized with chloral hydrate ( $4 \%, 1 \mathrm{ml} / 100 \mathrm{gm}$, intraperitoneally), and heparin $(1000 \mathrm{U} / \mathrm{ml}, 0.1 \mathrm{ml} / 100 \mathrm{gm})$ was administered via the femoral vein. Both superior venae cavae were ligated and the heart was excised and perfused retrogradely via the aorta at $37^{\circ} \mathrm{C}$ and at a pressure of $100 \mathrm{~cm} \mathrm{H}_{2} \mathrm{O}$ (Langendorff preparation). The inferior vena cava was ligated and coronary sinus effluent was collected from the pulmonary artery for determinations of coronary flow and myocardial oxygen consumption.

Left ventricular function was continuously monitored by a pressure transducer connected to a fluid-filled latex balloon inserted into the left ventricle across the mitral valve; end-diastolic pressure was 5 to $12 \mathrm{~mm} \mathrm{Hg}$. During stabilization hearts were paced at 300 beats/min by way of the right atrium if the intrinsic rate fell below this value. Myocardial oxygen consumption was calculated from the partial oxygen pressures in the inflow and outflow perfusates and the coronary flow rate. The solubility of oxygen was taken to be $3.1 \times 10^{-5} \mathrm{ml} / 100 \mathrm{ml} / \mathrm{mm} \mathrm{Hg}$, and the conversion from volume to moles of oxygen was 22.4 $\mathrm{ml} / \mathrm{mmol}$ oxygen $\left(\right.$ at $\left.273^{\circ} \mathrm{K}\right)$, multiplied by $\left(310^{\circ} / 273^{\circ} \mathrm{K}\right.$ ) to convert to the experimental temperature of $37^{\circ} \mathrm{C}$.

Perfusate composition. Throughout all phases of all experiments (except as noted below) the composition of the perfusate was as follows (in millimoles per liter): 118 $\mathrm{NaCl}, 4.7 \mathrm{KCl}, 1.2 \mathrm{MgSO}_{4}, 1.2 \mathrm{NaH}_{2} \mathrm{PO}_{4}, 25 \mathrm{NaHCO}_{3}, 1.2$ $\mathrm{CaCl}_{2}, 5.5$ glucose, 1.2 lactate, 0.12 pyruvate, 0.17 acetoacetate, 0.35 mixed fatty acids (see Table I), and bovine serum albumin, $7.5 \mathrm{gm} / \mathrm{L}$. These are the substrate concentrations present in the serum of a fed, rested rat. ${ }^{16}$ The "unlabeled" perfusate contained these substrates but without ${ }^{13} \mathrm{C}$ enrichment. The "labeled" perfusate contained these substrates at the same concentration but with the ${ }^{13} \mathrm{C}$ enrichment patterns described earlier. In all modifications of the perfusion medium (addition of potassium chloride with or without addition of aspartate and glutamate), the sodium chloride concentration was reduced to maintain constant perfusate osmolarity throughout all experiments. The perfusate was equilibrated with 95\% oxygen and 5\% carbon dioxide with a thin-film oxygenator. The perfusate was not recirculated.

Experimental protocols. After a 20-minute stabilization period with unlabeled perfusate, hearts were randomly assigned to one of three groups. Controls (group 1) were switched to the labeled medium, perfusion was continued for 30 minutes, and the heart was freezeclamped. The potassium cardioplegia group (group 2) was switched to the labeled perfusate with the potassium chloride concentration increased to $20 \mathrm{mmol} / \mathrm{L}$ (and the sodium chloride concentration correspondingly decreased). Pacing was discontinued immediately on switching to the arrest medium. Perfusion was continued for 30 minutes, and the heart was freeze-clamped. The gluta- 


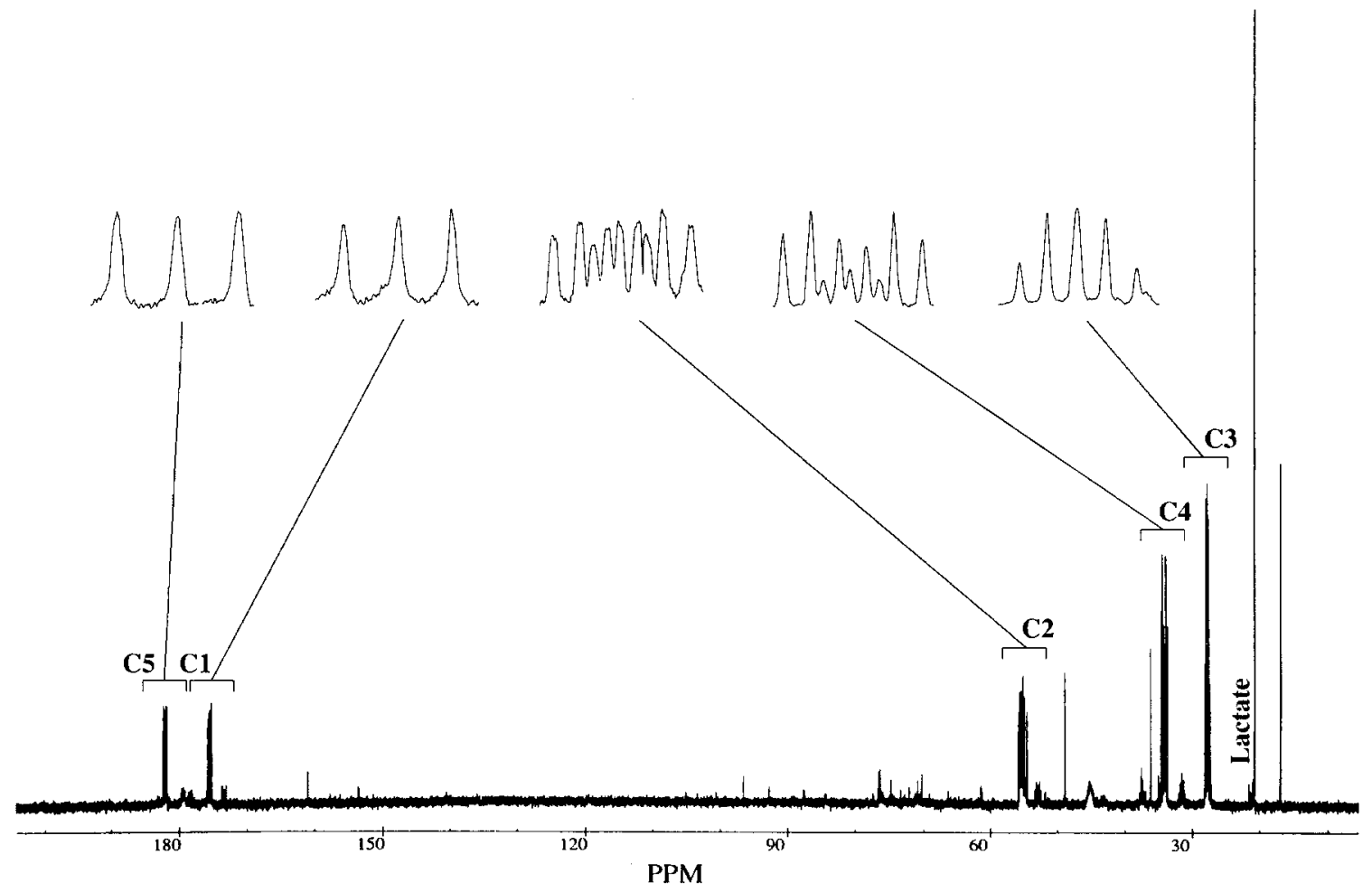

Fig. 1. Proton decoupled ${ }^{13} \mathrm{C}-\mathrm{NMR}$ spectrum of an extract from a control heart. PPM, Parts per million.

mate plus aspartate group (group 3) was switched to the labeled perfusate with the following modifications: potassium chloride, $20 \mathrm{mmol} / \mathrm{L}$; unlabeled aspartate, 13 $\mathrm{mmol} / \mathrm{L}$; unlabeled glutamate, $13 \mathrm{mmol} / \mathrm{L}$. The concentrations of aspartate and glutamate were taken from the reports of Rosenkranz, ${ }^{6}$ Allen, ${ }^{10}$ and their associates. Hearts were perfused for 30 minutes and freeze-clamped. At the end of each experiment, nonventricular tissue was rapidly trimmed and hearts were freeze-clamped in aluminum tongs and stored in liquid nitrogen.

So that metabolism of exogenous glutamate and aspartate in the citric acid cycle could be tracked directly, additional perfusions were done according to the protocol for group 3 for the final 30 minutes with [U- ${ }^{13} \mathrm{C}$ ]glutamate $(13 \mathrm{mmol} / \mathrm{L})$ as the only enriched substrate (the perfusate including aspartate was otherwise not enriched). In additional hearts, the identical protocol was followed with [U- ${ }^{13} \mathrm{C}$ ]aspartate $(13 \mathrm{mmol} / \mathrm{L})$ as the only labeled component. In these experiments the ${ }^{13} \mathrm{C}$ label originated in either glutamate or aspartate, but not both. Because the remainder of the experimental conditions were identical to those in group 3, the detection of ${ }^{13} \mathrm{C}$ enrichment in intermediates or products of the citric acid cycle would confirm entry of either glutamate or aspartate into the cycle.

Tissue extraction and ${ }^{13} \mathrm{C}$-nuclear magnetic resonance spectroscopy. Frozen hearts were extracted with cold $4 \%$ perchloric acid ( $1 \mathrm{gm}$ tissue per $4 \mathrm{ml}$ perchloric acid) and centrifuged. The supernatant was neutralized with potassium hydroxide, centrifuged, and lyophilized. After the extract was dissolved in $0.5 \mathrm{ml}$ of deuterium oxide, proton- decoupled ${ }^{13} \mathrm{C}$-nuclear magnetic resonance (NMR) spectra were obtained in a $5 \mathrm{~mm}$ tube at $100.3 \mathrm{MHz}$ on a 9.4 T Bruker Omega spectrometer (Bruker Instruments, Inc., Billerica, Mass.). Sixteen thousand data points over 22 to $26 \mathrm{KHz}$ were acquired with a 3-second delay between 45-degree carbon pulses. Spectra were zero-filled to 32,000 points before Fourier transformation. Relative multiplet areas in the glutamate carbon resonances were determined with the use of commercial software (NMR-1, Tripos Associates, St. Louis, Mo.).

Metabolic analysis. With the substrates described earlier, the acetyl group of acetyl CoA will be labeled in four possible patterns: enriched in carbon 1 (derived only from acetoacetate), enriched in carbon 2 (derived only from pyruvate or lactate in the perfusate), enriched in both carbons 1 and 2 (derived only from fatty acids in the perfusate), or unenriched (derived from glycogen, tissue triglycerides, or glucose in the perfusate). Each of these possible labeling patterns is reflected in the enrichment pattern of the 4 and 5 carbons of glutamate, which are easily distinguished in the ${ }^{13} \mathrm{C}-\mathrm{NMR}$ spectrum (see Figs. 1 and 2 ). The multiplets from carbons 4 and 5 plus the ratio of areas in carbons 4 and 3 were used to calculate the fraction of acetyl $\mathrm{CoA}$ derived from each substrate:

$$
\text { Fraction from fatty acids }=(\mathrm{C} 4 / \mathrm{C} 3) \cdot \mathrm{C} 4 \mathrm{Q}
$$

Fraction from lactate or pyruvate $=(\mathrm{C} 4 / \mathrm{C} 3) \cdot \mathrm{C} 4 \mathrm{D} 34$

Fraction from acetoacetate $=(\mathrm{C} 4 / \mathrm{C} 3) \cdot \mathrm{C} 4 \mathrm{Q} \cdot(\mathrm{C} 5 \mathrm{~S} / \mathrm{C} 5 \mathrm{D})$ 


\section{Glutamate}
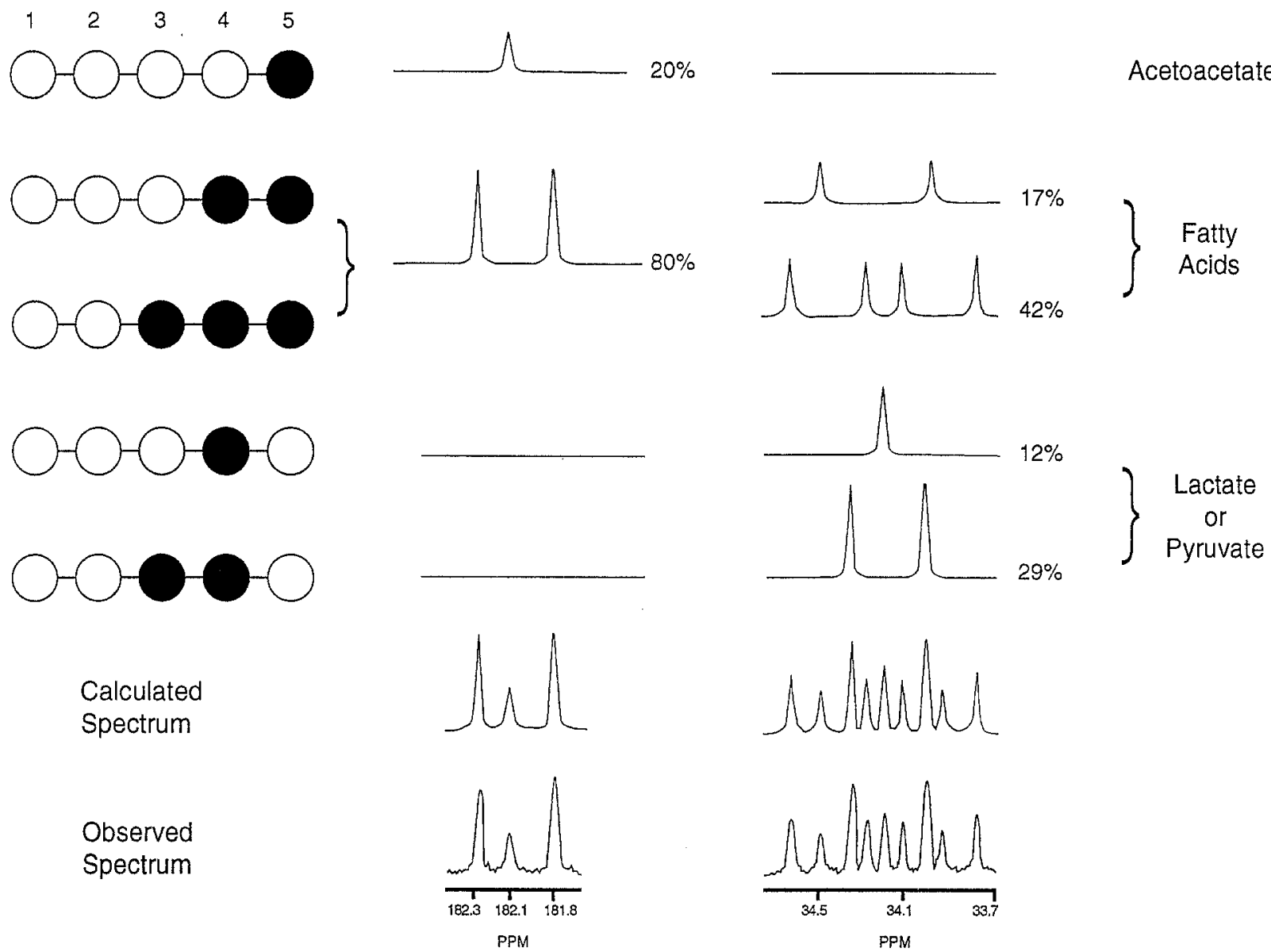

Observed

Spectrum

PPM

PPM

Fig. 2. Nonsteady-state analysis of glutamate $\mathrm{C} 5$ and $\mathrm{C} 4$. Proton-decoupled ${ }^{13} \mathrm{C}-\mathrm{NMR}$ spectra of the $\mathrm{C} 4$ and $\mathrm{C} 5$ carbons of glutamate are depicted in the lower panels. These spectra may be resolved into multiplets corresponding to the labeling patterns that may arise in the glutamate molecule. The relative areas of each multiplet correspond to the relative utilization of its corresponding substrate source. PPM, Parts per million.

where $\mathrm{C} 4 / \mathrm{C} 3$ is the ratio of resonance areas for carbons 4 and 3 of glutamate. The multiplets (C4Q, C4D34, and C5D) occur when a single resonance is split as a consequence of carbon-carbon coupling between adjacent ${ }^{13} \mathrm{C}$ nuclei, designated J. C4D34 is the area of the doublet resulting from enrichment in both carbons 3 and 4 ; $4 \mathrm{Q}$ is the area of the quartet resulting from enrichment in carbons 3, 4, and 5, and C5D is the area of the doublet resulting from enrichment in carbons 4 and 5 (definitions from Malloy, Sherry, and Jeffrey ${ }^{17}$; equations derived from Malloy and associates ${ }^{18}$ ). For example, if $\mathrm{C} 4 / \mathrm{C} 3=$ 1.13 and $\mathrm{C} 4 \mathrm{Q}=0.51$, then the fraction of acetyl $\mathrm{CoA}$ derived from fatty acids is $1.13 \cdot 0.51=0.58$. The fraction from unlabeled sources (triglycerides, glycogen, or glucose) was determined by difference from 1 . The addition of glutamate $(13 \mathrm{mmol} / \mathrm{L})$ in group 3 raised the possibility that ${ }^{13} \mathrm{C}$ present in natural abundance $(1.1 \%)$ may be detected. However, the other multiplets (C4D34, C4D45, and $\mathrm{C} 4 \mathrm{Q}$ ) cannot be the result of natural abundance ${ }^{13} \mathrm{C}$.
Because C4D34/C4Q $=\mathrm{C} 4 \mathrm{~S} / \mathrm{C} 4 \mathrm{D} 45,{ }^{18}$ the area of the singlet resulting from natural abundance ${ }^{13} \mathrm{C}$ in perfusate glutamate can be determined. This correction was minimal, and both the observed and the corrected data are reported (Table II). All metabolic analyses were performed with the corrected data, but this had little effect on the metabolic results. The multiplets from all five glutamate carbons were also analyzed for control hearts by means of the steady-state analysis. ${ }^{17}$

Statistical analysis. Results are presented as mean \pm standard deviation and were compared by means of one-way analysis of variance (SAS, Inc., Cary, N.C.).

\section{Results}

Myocardial function and oxygen consumption. Hearts from the control group remained stable throughout the 50-minute perfusion period; rate- 
Table II. Multiplet areas in the ${ }^{13} C-N M R$ spectra

\begin{tabular}{llcccc}
\hline $\begin{array}{c}\text { Glutamate carbon } \\
\text { resonances } \\
\text { (chemical shift) }\end{array}$ & $\begin{array}{c}\text { Multiplet } \\
\text { or relative }\end{array}$ & $\begin{array}{c}\text { Control } \\
\text { (group 1) }\end{array}$ & $\begin{array}{c}\text { Potassium } \\
\text { arrest } \\
\text { (group 2) }\end{array}$ & $\begin{array}{c}\text { Glutamate }+ \\
\text { aspartate }+ \\
\text { potassium arrest } \\
\text { (group 3) }\end{array}$ & $\begin{array}{c}\text { Corrected } \\
\text { (group 3) }\end{array}$ \\
\hline Carbon 1 & $\mathrm{S}$ & $0.65 \pm 0.02$ & $0.70 \pm 0.06$ & $0.63 \pm 0.12$ & $0.61 \pm 0.14$ \\
(175.2 ppm) & $\mathrm{D}$ & $0.35 \pm 0.02$ & $0.30 \pm 0.06$ & $0.37 \pm 0.12$ & $0.39 \pm 0.14$ \\
Carbon 2 & $\mathrm{S}$ & $0.13 \pm 0.02$ & $0.51 \pm 0.11$ & $0.56 \pm 0.15$ & $0.52 \pm 0.16$ \\
$(55.2 \mathrm{ppm}$ ) & $\mathrm{D} 23$ & $0.17 \pm 0.01$ & $0.09 \pm 0.04$ & $0.07 \pm 0.02$ & $0.08 \pm 0.03$ \\
& $\mathrm{D} 12$ & $0.27 \pm 0.02$ & $0.30 \pm 0.08$ & $0.30 \pm 0.09$ & $0.31 \pm 0.10$ \\
Carbon 3 & $\mathrm{Q}$ & $0.42 \pm 0.04$ & $0.11 \pm 0.15$ & $0.08 \pm 0.07$ & $0.08 \pm 0.08$ \\
(27.6 ppm) & $\mathrm{S}$ & $0.13 \pm 0.04$ & $0.64 \pm 0.08$ & $0.61 \pm 0.19$ & $0.58 \pm 0.21$ \\
& $\mathrm{D}$ & $0.45 \pm 0.02$ & $0.33 \pm 0.06$ & $0.32 \pm 0.11$ & $0.34 \pm 0.12$ \\
Carbon 4 & $\mathrm{T}$ & $0.42 \pm 0.05$ & $0.03 \pm 0.04$ & $0.07 \pm 0.09$ & $0.08 \pm 0.10$ \\
(34.2 ppm) & $\mathrm{S}$ & $0.06 \pm 0.02$ & $0.12 \pm 0.03$ & $0.22 \pm 0.15$ & $0.17 \pm 0.17$ \\
& $\mathrm{D} 34$ & $0.08 \pm 0.03$ & $0.03 \pm 0.03$ & $0.03 \pm 0.02$ & $0.03 \pm 0.02$ \\
Carbon 5 & $\mathrm{D} 45$ & $0.35 \pm 0.03$ & $0.65 \pm 0.04$ & $0.56 \pm 0.07$ & $0.60 \pm 0.09$ \\
(181.6 ppm) & $\mathrm{Q}$ & $0.51 \pm 0.03$ & $0.20 \pm 0.05$ & $0.19 \pm 0.11$ & $0.21 \pm 0.11$ \\
(Area carbon 4)/ & $\mathrm{S}$ & $0.31 \pm 0.03$ & $0.74 \pm 0.06$ & $0.67 \pm 0.16$ & $0.64 \pm 0.17$ \\
(Area carbon 3) & $\mathrm{D}$ & $0.69 \pm 0.03$ & $0.26 \pm 0.06$ & $0.33 \pm 0.16$ & $0.36 \pm 0.17$ \\
& $\mathrm{C} 4 \mathrm{C} 3$ & $1.13 \pm 0.05$ & $1.09 \pm 0.12$ & $1.22 \pm 0.26$ & $1.25 \pm 0.24$ \\
\hline
\end{tabular}

Each letter refers to the area of that multiplet relative to the total resonance area of that carbon: $S$, singlet; $D$, doublet resulting from $\mathbf{J}$ coupling with a single adjacent carbon atom, as noted; $Q$, quartet (doublet of doublets); $T$, triplet resulting from glutamate labeled in $\mathrm{C} 2, \mathrm{C} 3$, and $\mathrm{C} 4$. The area of the $\mathrm{C} 4$ relative to the $\mathrm{C} 3$ resonance is $\mathrm{C} 4 \mathrm{C} 3$ ( $n=8$ in each group).

pressure product changed less than $10 \%$ during perfusion with ${ }^{13} \mathrm{C}$-labeled compounds. Oxygen consumption in the control group was $53.3 \pm 10.0$ $\mu \mathrm{mol} / \mathrm{gm}$ dry weight per minute. Hearts exposed to a $20 \mathrm{mmol} / \mathrm{L}$ concentration of potassium (groups 2 and 3 ) ceased beating within 15 seconds of exposure to the arresting medium (separate experiments showed complete recovery of mechanical function after switching back to a $4.7 \mathrm{mmol} / \mathrm{L}$ concentration of potassium chloride). At the end of 30 minutes of potassium arrest, oxygen consumption in group 2 was $21.6 \pm 6.7 \mu \mathrm{mol} / \mathrm{gm}$ dry weight per minute, significantly less than in the control group $(p<$ $0.05)$. Oxygen consumption in hearts exposed to glutamate plus aspartate during potassium arrest (group 3) was $16.7 \pm 1.7 \mu \mathrm{mol} / \mathrm{gm}$ dry weight per minute, not significantly different from values in hearts exposed to potassium arrest alone (group 2). Together, these results showed that potassium chloride arrest produced a significant and substantial decrease in oxygen consumption, but that glutamate plus aspartate had no significant additional effect on oxygen consumption.

${ }^{13} \mathrm{C}-\mathrm{NMR}$ spectra and selection of substrates for oxidation. The ${ }^{13} \mathrm{C}-\mathrm{NMR}$ spectra of hearts perfused under control conditions (see Fig. 1) were similar to those in previous reports ${ }^{19}$ and demonstrated that under these conditions all of the ${ }^{13} \mathrm{C}$-enriched substrates, even when present in low concentrations, were oxidized in the citric acid cycle. The relative intensities of the multiplets of glutamate are summarized in Table II. Analysis of these multiplets by the nonsteady-state method showed that fatty acids, as expected, contributed the majority of acetyl CoA, about $58 \%$, and that acetoacetate contributed most of the remaining oxidized carbon, about $24 \%$ (Table III). The remaining acetyl $\mathrm{CoA}$ originated either from lactate or pyruvate provided in the perfusate $(10 \%)$ or from unlabeled sources such as endogenous triglyceride stores, glycogen, or unlabeled glucose in the perfusate. These unlabeled sources contributed only $8 \%$ of the total acetyl CoA. The sources of acetyl CoA calculated by the steady-state analysis were virtually identical to the nonsteadystate results: fatty acids, $57 \% \pm 4 \%$; acetoacetate, $26 \% \pm 3 \%$; lactate or pyruvate, $10 \% \pm 3 \%$; unlabeled sources, $6 \% \pm 4 \%$.

Potassium arrest dramatically altered the ${ }^{13} \mathrm{C}$ NMR spectrum of glutamate (Fig. 3 and Table II), indicating different sources of acetyl CoA. Fig. 3 shows a decrease in the doublet detected in the C5 of glutamate, which indicates a decrease in the oxidation of fatty acids relative to acetoacetate. The nonsteady-state analysis of the sources of acetyl CoA (see Table III) found a significant decrease in both fatty acid and lactate contribution to acetyl CoA caused by potassium arrest, which was balanced by a substantial increase in contribution from acetoacetate. Thus, although fatty acids are the preferred substrate for oxidation in normally per- 
Table III. Fraction of acetyl CoA derived from available substrates

\begin{tabular}{lcccc}
\hline & \multicolumn{3}{c}{ Contribution to acetyl CoA (\%) } \\
\cline { 2 - 5 } \multicolumn{1}{c}{ Experimental group } & $\begin{array}{c}\text { Lactate or } \\
\text { pyruvate }\end{array}$ & Fatty acids & Acetoacetate & Unlabeled \\
sources
\end{tabular}

The contribution of exogenous substrates to acetyl CoA was determined from the data in Table II ( $n=8$, each group). The contribution of each substrate to acetyl $\mathrm{CoA}$ under each experimental condition was compared by analysis of variance.

*The contribution of a substrate to acetyl CoA was different from the other two groups at $p<0.05$.

fused hearts, potassium chloride arrest shifts substrate preference to acetoacetate.

The addition of unlabeled glutamate and aspartate caused little further change in the ${ }^{13} \mathrm{C}$-NMR spectra (Fig. 3 and Table III). The contribution of acetoacetate to acetyl $\mathrm{CoA}$ was significantly less than was the contribution of potassium arrest alone, but the magnitude of this effect was modest.

Metabolism of glutamate and aspartate. Although glutamate and aspartate did not have a dramatic effect on the profile of substrate selection, direct metabolism as intermediates of the citric acid cycle had not been excluded, because the studies described herein determined only the sources of acetyl CoA and not the activity of other pathways feeding the cycle. Therefore a small number of hearts were perfused with the same substrate mixture as group 3, except that the site of ${ }^{13} \mathrm{C}$ enrichment was either $\left[\mathrm{U}_{-}{ }^{13} \mathrm{C}\right]$ glutamate $(13 \mathrm{mmol} / \mathrm{L})$ or $\left[\mathrm{U}_{-}{ }^{13} \mathrm{C}\right.$ ]aspartate $(13 \mathrm{mmol} / \mathrm{L})$.

Under these conditions, [U- ${ }^{13} \mathrm{C}$ ]glutamate supplied in the perfusate is trapped in the interstitial space and therefore included in the freezeclamped tissue, where the ${ }^{13} \mathrm{C}$ label will be detected by NMR. This experiment cannot distinguish extracellular glutamate from intracellular glutamate that has not been metabolized, because the ${ }^{13} \mathrm{C}$ labeling patterns are identical. However, once $\left[\mathrm{U}_{-}{ }^{13} \mathrm{C}\right]$ glutamate enters the citric acid cycle (via $\alpha$-ketoglutarate), it will be metabolized to $\left[\mathrm{U}-{ }^{13} \mathrm{C}\right]$ oxaloacetate. Condensation with unlabeled acetyl CoA (the available oxidizable substrates were not all enriched in this experiment) produces $\left[1,2,3-{ }^{13} \mathrm{C}\right]$ citrate and, subsequently, $\left[1,2,3-{ }^{13} \mathrm{C}\right]$ glutamate. This labeling pattern is easily distinguished from $\left[\mathrm{U}^{13} \mathrm{C}\right]$ glutamate, because enrichment in carbon 3 is detected as a doublet resulting from $\boldsymbol{J}_{2,3}$ (rather than the apparent triplet that would be produced as a result of $J_{2,3}$ and $\mathrm{J}_{3,4}$ from [ $\mathrm{U}^{-13} \mathrm{C}$ ]glutamate in the perfusate).
Metabolism of $\left[\mathrm{U}^{13} \mathrm{C}\right]$ glutamate was not detected (data not shown).

There are two possible pathways for aspartate metabolism after transamination to oxaloacetate: (1) condensation with unlabeled acetyl CoA to form citrate or (2) decarboxylation to pyruvate. So that aspartate metabolism could be monitored directly, additional perfusions were done with $\left[\mathrm{U}_{-}^{13} \mathrm{C}\right]$ aspartate $(13 \mathrm{mmol} / \mathrm{L})$ as the only labeled compound. If aspartate enters the cycle via transamination, $\left[\mathrm{U}-{ }^{13} \mathrm{C}\right]$ oxaloacetate will be produced, which will combine with unlabeled acetyl $\mathrm{CoA}$ and subsequently form $\alpha$-ketoglutarate enriched in carbons 1 , 2 , and 3 . The corresponding glutamate ([1,2,3${ }^{13} \mathrm{Clglutamate)}$ will show a doublet resulting from ${ }^{13} \mathrm{C}-{ }^{13} \mathrm{C}$ spin-spin coupling in carbon 3 at about 27.6 ppm. A small doublet was indeed detected, showing that a small amount of glutamate was derived from the pathway $\left[\mathrm{U}_{-}{ }^{13} \mathrm{C}\right]$ aspartate $\rightarrow\left[\mathrm{U}_{-}{ }^{13} \mathrm{C}\right.$ loxaloacetate $\rightarrow\left[1,2,3-{ }^{13} \mathrm{C}\right]$ citrate $\rightarrow \rightarrow\left[1,2,3{ }^{-13} \mathrm{C}\right] \alpha$-ketoglutarate (Fig. 4, $A$ ). The singlet is primarily caused by ${ }^{13} \mathrm{C}$ present in glutamate at natural abundance $(1.1 \%)$. Therefore much less than $1 \%$ of $\alpha$-ketoglutarate was derived from the aspartate provided in the perfusate.

The alternative pathway for aspartate metabolism, [U- $\left.{ }^{13} \mathrm{C}\right]$ aspartate $\rightarrow\left[\mathrm{U}_{-}{ }^{13} \mathrm{C}\right]$ oxaloacetate $\rightarrow$ $\left[\mathrm{U}-{ }^{13} \mathrm{C}\right]$ pyruvate $\rightarrow\left[1,2-{ }^{13} \mathrm{C}\right]$ acetyl $\mathrm{CoA} \rightarrow[4,5-$ $\left.{ }^{13} \mathrm{C}\right]$ citrate, yields $\left[4,5^{-13} \mathrm{C}\right]$ glutamate (see Fig. $4, B$ ). In this case, $\mathrm{J}_{4,5}$ (but not $\mathrm{J}_{3,4}$ ) will be detected in the carbon 4 resonance of glutamate at $34.2 \mathrm{ppm}$. This multiplet (the doublet in $\mathrm{C} 4$ resulting from $\mathbf{J}_{4,5}$ ) was detected, although the resonances were again small compared with the singlet. Because the singlet at $34.2 \mathrm{ppm}$ is derived primarily from ${ }^{13} \mathrm{C}$ present at natural abundance $(1.1 \%)$, these observations indicate that aspartate indeed is oxidized via acetyl CoA in the citric acid cycle, but that it is quantitatively negligible: less than $1 \%$ of acetyl $\mathrm{CoA}$ was derived from aspartate. 

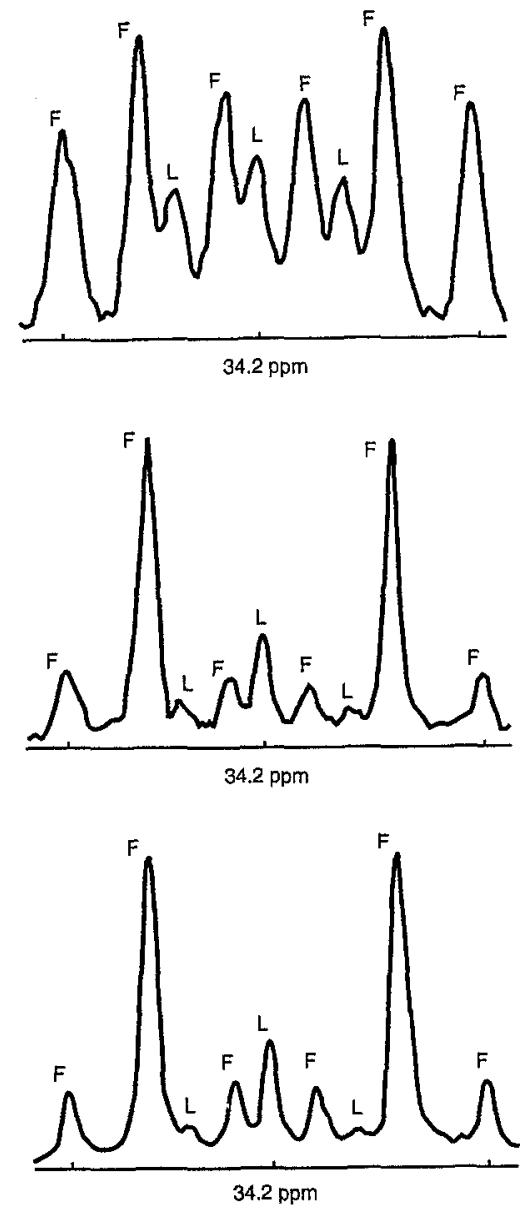

Glutamate C4
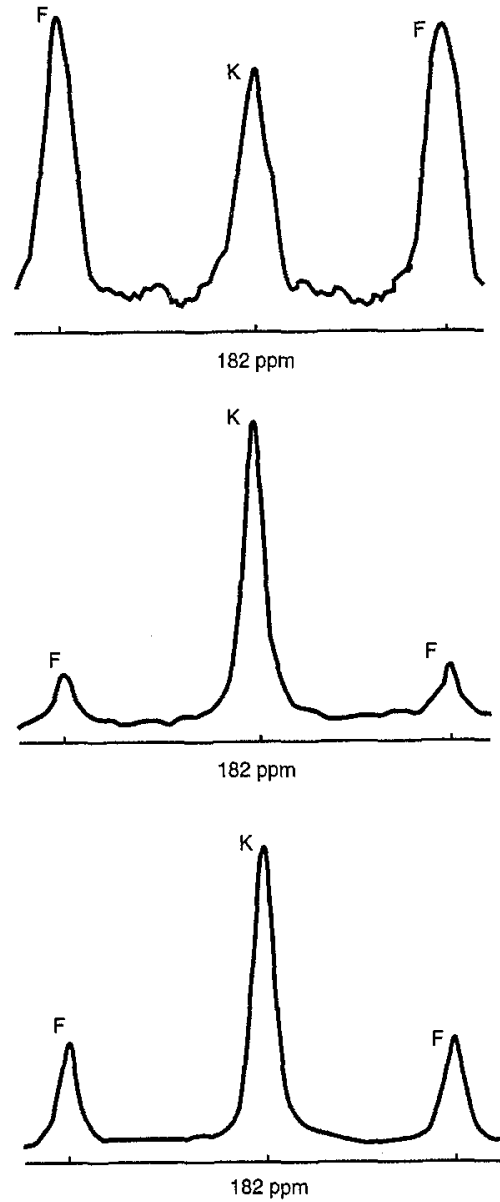

Glutamate C5
Group 1 (Control)

Group $2(\mathrm{KCl})$

Fig. 3. Representative glutamate $\mathrm{C} 4$ and $\mathrm{C} 5$ spectra from hearts from each group. Simple inspection indicates that peaks labeled $F$ and $L$ (for fatty acids and lactate, respectively) are reduced in both cardioplegia groups, whereas those labeled $K$ (for ketones) are increased. $G A$, Glutamate and aspartate; ppm, parts per million.

Anaplerosis. The entry of carbon skeletons into the citric acid cycle via pathways such as pyruvate carboxylation or net flow of an amino acid into the cycle through a transamination reaction has been termed anaplerosis. The ratio of flux through these combined pathways relative to citric acid cycle flux has been given the variable name $y$. Analysis ${ }^{17}$ of the data in Table II found a $y$ of $11 \% \pm 3 \%$ under control conditions, and a significant fraction of the carbon skeletons (about $0.48 \pm 0.05$ ) entering the citric acid cycle through anaplerosis was derived from the pyruvate plus lactate pool in the perfusate. Because earlier studies $^{20,21}$ have shown that the assumption of steady state may not be reliable after 30 minutes during potassium chloride arrest, the steady-state analysis was not applied in those groups.

\section{Discussion}

Selection of substrates for oxidation: effects of cardioplegia and amino acids. Unlike most studies of isolated hearts, five oxidizable substrates that are normally present in blood were provided in this experiment. Under control conditions, the sources of acetyl CoA were similar to those reported recently by Jeffrey and colleagues. ${ }^{19}$ The current study confirms the relatively large contribution of acetoacetate even in the presence of long-chain fatty acids under control conditions. Potassium chloride arrest inhibited oxidation of both fatty acids and the lactate plus pyruvate pool, and acetoacetate became the dominant source of acetyl CoA. The uptake of fatty acids is a carrier-mediated process, ${ }^{22}$ and the transmembrane transport of fatty acids is inhibited 
A

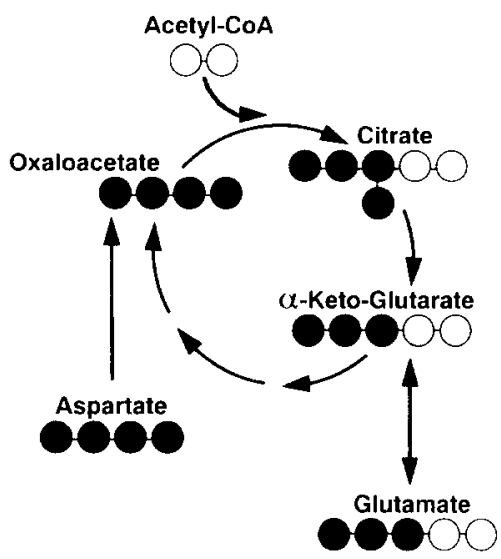

Glutamate C3 Spectrum

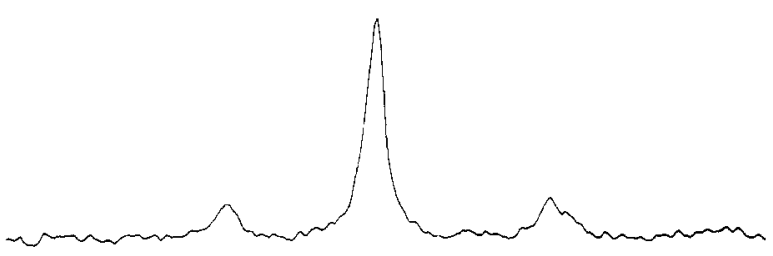

28.20
27.80

PPM
B

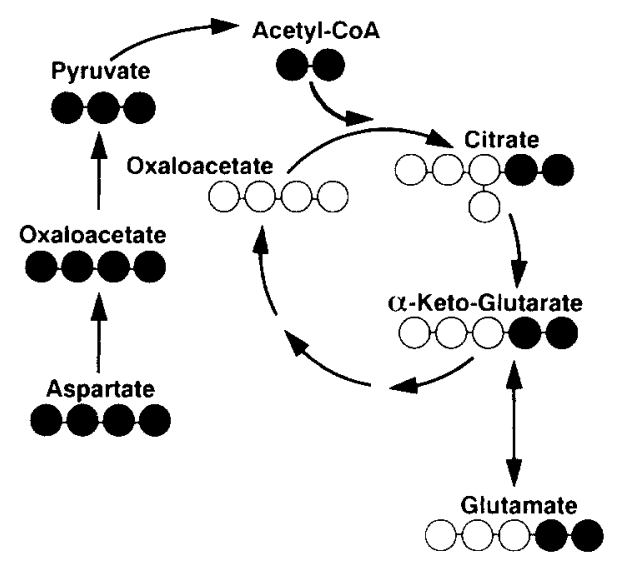

Glutamate C4 Spectrum

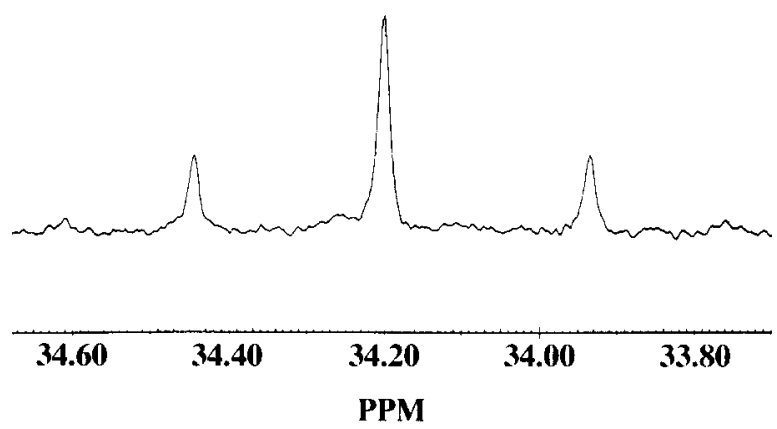

Fig. 4. Pathways for $\left[\mathrm{U}_{-}{ }^{13} \mathrm{C}\right]$ aspartate entry into the citric acid cycle. A, If $\left[\mathrm{U}_{-}{ }^{13} \mathrm{C}\right]$ aspartate (filled circles) is metabolized to oxaloacetate and citrate, then ${ }^{13} \mathrm{C}^{13} \mathrm{C}$ coupling must be detected as a doublet in the glutamate C3 resonance, shown in the lower spectrum. B, If [U- ${ }^{13} \mathrm{C}$ ]aspartate forms oxaloacetate and subsequently generates pyruvate, this labeled pyruvate could form labeled acetyl CoA and produce glutamate enriched in carbons 4 and 5 . This pattern will be detected as a doublet in the glutamate $\mathrm{C} 4$ caused by ${ }^{13} \mathrm{C}^{13} \mathrm{C}$ coupling between carbons 4 and 5. PPM, Parts per million.

by depolarization in the isolated liver. ${ }^{23}$ High concentrations of potassium also stimulate myocardial pyruvate dehydrogenase kinase and thereby reduce pyruvate dehydrogenase activity. ${ }^{24}$ Because oxidation of both lactate and pyruvate in the citric acid cycle requires flux through this enzyme complex, its inhibition may reduce carbohydrate contribution to acetyl CoA. Together, these effects of potassium chloride should inhibit oxidation of both carbohydrates and long-chain fatty acids, which would be reflected as an increase in the contribution of the only remaining substrate, acetoacetate, to acetyl CoA.

The addition of glutamate and aspartate had little further effect on substrate utilization patterns. Earlier in vivo studies ${ }^{14}$ found that the profile of substrate selection is sensitive to glutamate, but this effect was likely mediated by systemic changes in substrate and insulin concentrations.

Minimal entry of labeled amino acids into the citric acid cycle. Studies performed with ${ }^{13} \mathrm{C}$-labeled glutamate failed to demonstrate entry of this amino acid into the cycle by any route. This conclusion contrasts with the report by Sanborn and associates ${ }^{12}$ who detected ${ }^{14} \mathrm{C}$-labeled carbon dioxide release and ${ }^{14} \mathrm{C}$-enriched succinate in myocardium exposed to ${ }^{14} \mathrm{C}$-enriched glutamate. However, as noted by these authors, the rate of glutamate metabolism to succinate or other relative flux measurements could not be determined. The current study differed in several respects, including species, potassium chloride arrest, and method of detecting metabolism of enriched glutamate. Hence, although the studies cannot be directly compared, one con- 
sistent interpretation is that the more sensitive technique $\left({ }^{14} \mathrm{C}\right.$ tracer analysis) detected glutamate metabolism, but that the quantitative significance is minimal relative to the activity of other pathways feeding the citric acid cycle.

The early documentation of ${ }^{14} \mathrm{C}$-labeled aspartate metabolism in the rabbit myocardium ${ }^{12}$ was later confirmed by studies with $\left[4-{ }^{11} \mathrm{C}\right]$ aspartate detected by positron computed tomography. ${ }^{25}$ The current study extended these observations by showing metabolism of aspartate via both anaplerosis (aspartate $\rightarrow$ oxaloacetate $\rightarrow$ citrate) and net oxidation (aspartate $\rightarrow \rightarrow$ acetyl CoA $\rightarrow$ citrate). However, the rate of aspartate metabolism through either pathway is negligible (probably less than $1 \%$ of total citric acid cycle flux). Together, these reports illustrate the complementariness of carbon radioisotope methods and ${ }^{13} \mathrm{C}-\mathrm{NMR}$. Radiotracer techniques detected amino acid metabolism with high sensitivity, whereas the ${ }^{13} \mathrm{C}-\mathrm{NMR}$ isotopomer analysis provided simultaneous measurements of other metabolic pathways.

Clinical relevance. This study did not find substantial effects of these amino acids on citric acid cycle function. These observations are consistent with those of Galiñanes, Chambers, and Hearse, ${ }^{26}$ who found that the addition of aspartate to a long-term cardioplegic storage solution had no effect after controlling for sodium concentration, and those of Crooke and associates, ${ }^{27}$ who found that the addition of amino acids offered no further benefit in their cardioplegic solutions. Although these amino acids have been studied as additives to cardioplegic solutions in clinical trials, some ${ }^{28}$ but not all $^{29}$ reports favor their use.

Study limitations. This model differed from some earlier studies because the heart was perfused in the absence of red cells (albumin was present). However, much of the experimental justification for amino acid supplementation is based on the crystalloid-perfused heart, and at least one report indicates that glutamate is effective only in crystalloid-perfused myocardium. ${ }^{9}$ The concentrations of substrates were based on those found in the fed, rested animal; the concentration during extracorporeal circulation may differ significantly. If the effects of amino acids are dependent on available substrate or an interaction among available substrate, ischemia and potassium ion concentration, then a significant effect may have been missed. Finally, our study was performed in rats. A beneficial effect limited to some species is possible, but other studies have reported functional benefits in many species including rats.

The technical assistance of Robert Y. Chao and Kimberley Ross is appreciated.

\section{REFERENCES}

1. Choong YS, Gavin JB, Armiger LC. Effects of glutamic acid on cardiac function and energy metabolism of rat heart during ischaemia and reperfusion. J Mol Cell Cardiol 1988; 20:1043-51.

2. Snaith CD, Wright G, Lofkin M. The effects of aspartate and 2-oxoglutarate upon glycolytic energy metabolites and mechanical recovery following global ischemia in isolated rat hearts. J Mol Cell Cardiol 1992;24:305-15.

3. Pisarenko OI, Rosenfeldt FL, Langley L, Conyers RAJ, Richards SM. Differing protection with aspartate and glutamate cardioplegia in the isolated rat heart. Ann Thorac Surg 1995;59:1541-8.

4. Haan CK, Lazar HL, Rivers S, Coady C, Shemin RJ. Improved myocardial preservation during cold storage using substrate enhancement. Ann Thorac Surg 1990;50:80-5.

5. Bittl JA, Shine KI. Protection of ischemic rabbit myocardium by glutamic acid. Am J Physiol 1983;245:H406-12.

6. Rosenkranz ER, Okamoto F, Buckberg GD, Robertson JM, Vinten-Johansen J, Bugyi H. Safety of prolonged aortic clamping with blood cardioplegia. III. Aspartate enrichment of glutamate-blood cardioplegia in energy-depleted hearts after ischemic and reperfusion injury. $\mathbf{J}$ Thorac Cardiovasc Surg 1986;91:428-35.

7. Julia PL, Kofsky ER, Buckberg GD, Young HH, Bugyi HI. Studies of myocardial protection in the immature heart. I. Enhanced tolerance of immature versus adult myocardium to global ischemia with reference to metabolic differences. J Thorac Cardiovasc Surg 1990;100:879-87.

8. Bush LR, Warren S, Mesh CL, Lucchesi BR. Comparative effects of aspartate and glutamate during myocardial ischemia. Pharmacology (Basel) 1981;23:297-304.

9. Engelman RM, Dobbs WA, Rousou JH, Meeran MK. Myocardial high energy phosphate replenishment during ischemic arrest: aerobic vs. anaerobic metabolism. Ann Thorac Surg 1982;33:453-8.

10. Allen BS, Buckberg GD, Fontan FM, Kirsh MM, Popoff G, Beyersdorff F, et al. Superiority of controlled surgical reperfusion versus percutaneous transluminal coronary angioplasty in acute coronary occlusion. J Thorac Cardiovase Surg 1993;105:864-84.

11. Beyersdorf F, Kirsh M, Buckberg GD, Allen BS. Warm glutamate/aspartate enriched blood cardioplegic solution for perioperative sudden death. J Thorac Cardiovasc Surg 1992; 104:1141-7.

12. Sanborn T, Gavin W, Berkowitz S, Perille T, Lesch M. Augmented conversion of aspartate and glutamate to succinate during anoxia in rat heart. Am J Physiol 1979; 273:H535-41.

13. Bolling SF, Childs KF, Ning XH. Amino acid substrate preloading and postischemic myocardial recovery. J Surg Res 1992;53:342-8.

14. Thomassen A, Nielsen TT, Bagger JP, Henningsen P. Effects of intravenous glutamate on substrate availability 
and utilization across the human heart and leg. Metabolism 1991;40:378-84.

15. Jessen ME, Kovarik TE, Jeffrey FM, Sherry AD, Storey CJ, Chao RY, et al. Effects of amino acids on substrate selection, anaplerosis, and left ventricular function in the ischemic reperfused rat heart. J Clin Invest 1993;92:831-9.

16. Remesy C, Demigne C. Changes in availability of glucogenic and ketogenic substrates and liver metabolism in fed or starved rats. Ann Nutr Metab 1983;27:57-70.

17. Malloy CR, Sherry AD, Jeffrey FM. Evaluation of carbon flux and substrate selection through alternate pathways involving the citric acid cycle of the heart by ${ }^{13} \mathrm{C}$ NMR spectroscopy. J Biol Chem 1988;263:6964-71.

18. Malloy CR, Thompson JR, Jeffrey MH, Sherry A. Contribution of exogenous substrates to acetylcoenzyme A: measurement by ${ }^{13} \mathrm{C}$ NMR under nonsteady-state conditions. Biochemistry 1990;29:6756-61.

19. Jeffrey FM, Diczku V, Sherry AD, Malloy CR. Substrate selection in the isolated working rat heart: effects of afterload, reperfusion, and concentration. Basic Res Cardiol 1995;90:388-96.

20. Weiss RG, Gloth ST, Kalil-Filho R, Chacko VP, Stern MD, Gerstenblith G. Indexing tricarboxylic acid cycle flux in intact hearts by carbon- 13 nuclear magnetic resonance. Circ Res 1992;70:392-408.

21. Lewandowski ED. Nuclear magnetic resonance evaluation of metabolic and respiratory support of work load in intact rabbit hearts. Circ Res 1992;70:576-82.

22. Stremmel W. Fatty acid uptake by isolated rat heart myocytes represents a carrier mediated transport process. J Clin Invest 1988;81:844-52.
23. Weisiger RA, Fitz JG, Scharschmidt BF. Hepatic oleate uptake. Electrochemical driving forces in intact rat liver. J Clin Invest 1989;83:411-20.

24. Robertson JG, Barron LL, Olson MS. Bovine heart pyruvate dehydrogenase kinase stimulation by monovalent ions. J Biol Chem 1989;264:11626-31.

25. Barrio JR, Egbert JE, Henze E, Schelbert HR, Baumgartner FJ. L-4- ${ }^{11} \mathrm{C}$ Aspartic acid: enzymatic synthesis, myocardial uptake, and metabolism. J Med Chem 1982;25:93-6.

26. Galiñanes M, Chambers DJ, Hearse DJ. Effect of sodium aspartate on the recovery of the rat heart from long-term hypothermic storage. J Thorac Cardiovasc Surg 1992;103: 521-31.

27. Crooke GA, Harris LJ, Grossi EA, Baumann FG, Esposito $\mathrm{R}$, Spencer FC, et al. Role of amino acids and enhancement cardioplegia in routine myocardial protection: experimental results. J Thorac Cardiovasc Surg 1993;106:497501.

28. Rosenkranz ER, Buckberg GD, Laks H, Mulder DG. Warm induction of cardioplegia with glutamate-enriched blood in coronary patients with cardiogenic shock who are dependent on inotropic drugs and intra-aortic balloon support. J Thorac Cardiovasc Surg 1983;86:507-18.

29. Bonchek LI, Burlingame MW, Vazales BE, Ferdinand NJ. Coronary bypass with substrate-enhanced cardioplegia versus non-cardioplegic technique for early revascularization in acute infarction. Eur J Cardiothorac Surg 1990;4: $124-9$.

30. Brockerhoff H, Hoyle RJ, Wolmark N. Positional distribution of fatty acids in triglycerides of animal depot fats. Biochim Biophys Acta 1966;116:67-72. 